\title{
A review of quality of life studies in Nigerian patients with psychiatric disorders
}

\section{O Aloba', O Fatoye², B Mapayi', S Akinsulore'1}

${ }^{1}$ Department of Mental Health, College of Health Sciences, Obafemi Awolowo University, Ile-Ife, Osun State, Nigeria 2Department of Mental Health, Obafemi Awolowo University Teaching Hospitals Complex, Ile-Ife, Osun State, Nigeria

\begin{abstract}
The concept of Quality of Life is becoming an increasingly important measure of the impact of psychiatric disorders and is now recognized as useful in the healthcare evaluation of patients with psychiatric disorders. The aim of this review was to document and analyze the research data on quality of life in Nigerian patients with psychiatric disorders. The electronic databases, Medline and Pubmed were searched for published articles on quality of life in Nigerian patients with psychiatric disorders. A total of 6 studies met the inclusion criteria. All the studies employed the generic World Health Organization Quality of Life Scale - Brief version, which is the only quality of life instrument whose psychometric properties have been evaluated among Nigerian patients with psychiatric disorders. Some of the studies revealed that quality of life was significantly associated with socio demographic factors such marital and employment status and social support. Poor quality of life was reported to be associated with illnessrelated factors such as co morbid medical problems, presence of anxiety and depressive symptoms and non adherence to medications. All the studies with the exception of two were conducted in centers located in South-western Nigeria. Quality of life in Nigerian patients suffering from psychiatric disorders is under-researched. There is need for more studies to prospectively investigate quality of life and associated factors among Nigerian patients with psychiatric disorders.
\end{abstract}

Keywords: Quality of life; Review; Nigeria; Psychiatric disorders

Received: 17-05-2012

Accepted: 27-1 1-2012

doi: http://dx.doi.org/10.4314/ajpsy.v16i5.44

\section{Introduction}

The World Health Organization (WHO) has defined quality of life (QOL) as "individuals' perception of their position in life in the context of the culture and value systems in which they live and in relation to their goals, expectations, standards and concerns". ${ }^{1}$ QOL as a concept has attained some prominence in social research studies since the 1970s and has been viewed as a broad concept which is concerned with overall well-being within the larger society and its principal focus is to enable people as optimally as possible to evaluate their goals and select their lifestyle. ${ }^{2} \mathrm{QOL}$ is a frequently used phrase, but lacks a concise definition. ${ }^{3,4}$ Various terms and phrases such as 'life satisfaction', 'functional statuses' and 'well being' have been used interchangeably. ${ }^{5}$

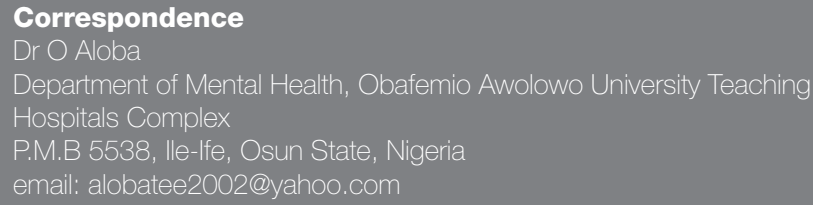

It is now generally preferred that patients themselves subjectively measure their QOL as this is now considered a better reflection of the patients' well-being and a more acceptable measure of actual experience and life satisfaction compared to the objectively evaluated. ${ }^{6}$ QOL has been considered an important variable when evaluating the outcomes of different psychiatric treatment modalities and relative cost. ${ }^{7}$ In addition to this, it can provide useful information that can be included into the planning and the evaluation of various treatment approaches and also places patients at the center of inquiry, with emphasis on their opinion. ${ }^{8}$ It has been proposed that QOL assessment introduces empathy into a system of health care delivery which tends to focus on symptomatic improvement and which is rather mechanistic. ${ }^{9}$

Studies of different specific psychiatric disorders have all demonstrated the adverse impact of these disorders on the quality of life and functioning of affected patients. Angermeyer and colleagues using the World Health Organization Quality of Life Scale -Bref version reported that QOL was significantly better in a group of patients whose depression remitted following treatment compared to those with persisting symptoms, and even 
among those in remission the QOL was worse than that of the general population with no improvement in QOL in the subsequent six months after treatment. ${ }^{10}$ Greater depressive symptoms have been associated with lower QOL. ${ }^{11}$ Apart from the negative impact on QOL, depression has also been found to have deleterious effects on psychosocial functioning that is equal or exceeds those of patients with chronic medical illnesses such as diabetes mellitus. ${ }^{12,13}$

Lowered QOL compared to healthy controls and reduced functioning and well-being even in the stable phase have been reported by patients with bipolar disorder. ${ }^{14}$ Patients with bipolar affective disorder have also reported that the disorder has a profoundly negative effect on their subjective QOL, notably in educational progress, vocation, financial functioning, and social and intimate relationship..$^{15}$ Likewise, QOL in patients with obsessive compulsive disorder revealed that a large majority of them indicated lowered social and emotional functioning and impairment of physical well-being. ${ }^{16}$ The reduction in QOL in patients with obsessive compulsive disorder has been found to be associated with the length of illness, depression and the number of compulsions. ${ }^{16}$

The review by Mendlowicz and Stein, reported that anxiety disorders, including; panic disorder, social phobia, posttraumatic stress disorder, generalized anxiety disorder, cause significant impairment in QOL and psychosocial functioning. ${ }^{17} \mathrm{QOL}$ has been described to be poor among substance dependent individuals compared to cohorts without substance use disorders. ${ }^{18,19}$ Smith and Larson, , using the MOS 36-item ShortForm Health Survey questionnaire ${ }^{20}$, found that individuals with substance-use disorders had significantly lower scores in the physical and mental functioning domains compared to the general population as well as patients with lung disease and diabetes and patients awaiting cardiac surgery. ${ }^{21}$ Mental illness has been shown to negatively affect most aspects of the patient's life, especially the physical and psychological aspects, as well as the affected individual's social, occupational and economic status. ${ }^{22}$ QOL has also been demonstrated to be lower in patients with chronic mental illnesses such as schizophrenia, when compared to the general population. ${ }^{23}$ A recent review of literature by Miroslava and colleagues, revealed that schizophrenia has been the main focus of QOL studies, thereby providing a narrow view of the impact of psychiatric disorders on QOL, although, recently, attention is now been given to QOL research concerning other psychiatric disorders. ${ }^{24}$ Given the global interest in QOL in patients, the present study aimed to provide a review of QOL studies in Nigerian patients with psychiatric disorders.

\section{Method}

\section{Search}

To locate studies that were eligible for this systematic review, we searched Medline (1990-2012) and Pubmed (1990-2012), between the 5th and 8th of March, 2012. The following search terms were used: 'quality of life', 'Nigerian patients', 'psychiatric disorders', 'schizophrenia', 'bipolar disorder', 'mania', 'depression', 'substance abuse', and 'alcoholism'. There were no limitations to the publication type. There are two postgraduate medical colleges in Nigeria (West African College of Physicians and the National Postgraduate Medical College). Since both colleges do not have an online database of the dissertations/theses of candidates who have successfully completed postgraduate specialty training, two of the authors (B.M and S.A) hand-searched the archives of these colleges to locate the dissertations/theses focused on QOL among Nigerians patients with psychiatric disorders.

\section{Selection criteria}

Two authors (A.O and F.F) independently reviewed abstracts and full articles to select studies eligible for this review. Studies were chosen if they met the following inclusion criteria: (1) QOL studies conducted in Nigeria, (2) involve patients aged 18 and above and, (3) employed the use of widely used generic instruments such as the WHOQOL-Bref.

\section{Data extraction}

For each eligible study, two authors (O.A and F.F), jointly extracted the following measures into a table; article authors, publishing journal name, year of publication, admission diagnosis, QOL instrument, time of data collection (e.g. outpatient or inpatient), sociodemographic variables such age of patients, and illness related variables such as comorbid medical disorders.

Following the hand-searching of the databases of the two postgraduate colleges, two dissertations focusing on QOL in Nigerian patients with psychiatric disorders were found. Both were conducted in centers in South-western Nigeria. One of the dissertations was conducted among patients with schizophrenia, examining QOL in association with sociodemographic and illness-related factors and was published in Acta Psychiatrica Scandinavica in 2009. The other dissertation examined QOL in patients with schizophrenia and its relationship with medication adherence and the findings were published in General Hospital Psychiatry in 2012 (see Table I).

\section{Results}

\section{Literature search}

The search through the electronic databases identified only 6 eligible papers published on the subject of QOL in Nigerian patients with psychiatry disorders. ${ }^{25-30}$ The studies identified for this review are shown in Table I.

\section{Study characteristics and design}

Of the 6 studies included in our systematic review, all with the exception of one were conducted in centers in South-western Nigeria. The sample sizes of the studies ranged from 99 to 313 participants. All the studies were cross-sectional in design. The generic WHOQOL-Bref Scale version was employed to evaluate QOL in all the studies. Four of the studies recruited the study participants from the out-patients clinics while two of them investigated QOL in the immediate period shortly after discharge.

\section{Factors associated with $Q O L$}

\section{- Socio demographic factors:}

These include gender and occupational status. ${ }^{26}$ Reduced subjective QOL was also found to correlate with poor social support in another study. ${ }^{27}$ In contrast, one of the reviewed studies reported no significant associations between sociodemographic factors and QOL. ${ }^{30}$

\section{- Illness-related factors:}

The presence of anxiety/depressive symptoms and comorbid 
Table I: Review of literature in QOL and psychiatric disorders in Nigeria.

\begin{tabular}{|c|c|c|c|c|c|}
\hline Author (s) & Journal & Year & Population & QOL instrument & Main findings \\
\hline Makanjuola et al & $\begin{array}{l}\text { Nigerian Medical } \\
\text { Practitioner }\end{array}$ & 2005 & $\begin{array}{l}135 \text { consenting adults with } \\
\text { schizophrenia in a university } \\
\text { teaching hospital in } \\
\text { north-central Nigeria }\end{array}$ & $\begin{array}{l}\text { World Health Organization } \\
\text { Quality of Life Scale-Brief } \\
\text { version (WHOQOL-Bref) }\end{array}$ & $\begin{array}{l}\text { There was a poor correlation between } \\
\text { objective indices and subjective QOL. } \\
\text { Gender and occupational status were the } \\
\text { socio-demographic and clinical variables } \\
\text { that correlated with subjective QOL. }\end{array}$ \\
\hline $\begin{array}{l}\text { Adewuya } \mathrm{AO}, \\
\text { Makanjuola } \mathrm{RO}\end{array}$ & Psychiatric Service & 2010 & $\begin{array}{l}99 \text { Adult outpatients with } \\
\text { schizophrenia. }\end{array}$ & WHOQOL-Bref & $\begin{array}{l}\text { In contrast to their poor living condition, } \\
\text { most of the patients expressed a high } \\
\text { level of satisfaction. }\end{array}$ \\
\hline $\begin{array}{l}\text { Olusina AK, } \\
\text { Ohaeri JU }\end{array}$ & $\begin{array}{l}\text { Journal of Social } \\
\text { Psychiatry and } \\
\text { Psychiatric } \\
\text { Epidemiology }\end{array}$ & 2003 & $\begin{array}{l}118 \text { patients aged } 18 \text { to } 60 \\
\text { diagnosed with schizophrenia } \\
\text { and affective disorders were } \\
\text { assessed } 2 \text { weeks after } \\
\text { discharge. }\end{array}$ & WHOQOL-Bref & $\begin{array}{l}\text { Items of highest satisfaction included } \\
\text { overall sense of well being and satisfaction } \\
\text { with self; satisfaction with personal } \\
\text { relationships and ability to work were } \\
\text { moderate; while there was dissatisfaction } \\
\text { with adequacy of money to met needs, } \\
\text { dependence on treatment and sex life. } \\
\text { There were no significant associations } \\
\text { between psychiatric diagnosis, socio- } \\
\text { demographic characteristics and QOL. }\end{array}$ \\
\hline $\begin{array}{l}\text { Adewuya } \mathrm{AO}, \\
\text { Makanjuola } \mathrm{RO}\end{array}$ & $\begin{array}{l}\text { Acta Psychiatrica } \\
\text { Scandinavica }\end{array}$ & 2009 & $\begin{array}{l}99 \text { outpatients with } \\
\text { schizophrenia. }\end{array}$ & WHOQOL-Bref & $\begin{array}{l}\text { Poor subjective QOL correlated with } \\
\text { anxiety/depressive symptoms, comorbid } \\
\text { medical problems, unemployment and } \\
\text { poor social support. }\end{array}$ \\
\hline Adelufosi et al & $\begin{array}{l}\text { General Hospital } \\
\text { Psychiatry }\end{array}$ & 2012 & $\begin{array}{l}313 \text { patients with DSM-IV } \\
\text { diagnosis of schizophrenia. }\end{array}$ & WHOQOL-Bref & $\begin{array}{l}\text { Medication nonadherence was significantly } \\
\text { associated with lower scores on all } \\
\text { domains and facets of QOL. }\end{array}$ \\
\hline Ohaeri et al & Psychopathology & 2004 & $\begin{array}{l}118 \text { recently recovered } \\
\text { Nigerian patients }\end{array}$ & WHOQOL-Bref & $\begin{array}{l}\text { The domains of the } 26 \text { item WHOQOL- } \\
\text { Bref contains heterogeneous items and } \\
\text { do not encompass the logical constructs } \\
\text { of subjective QOL. }\end{array}$ \\
\hline
\end{tabular}

$\S$ WHOQOL-Bref $=$ World Health Organisation Quality of Life-Bref Scale

medical problems were identified as correlates of poor subjective QOL in one study. ${ }^{27}$ In another study, medication nonadherence was reported to be associated with poor QOL. ${ }^{29}$

\section{Discussion}

To the knowledge of the authors, this is the first systematic review of quality of life studies in Nigerian patients with psychiatric disorders. This review has three main findings. First, all the studies employed the WHOQOL-Bref Scale version, which is a widely used generic QOL instrument. Second, QOL was evaluated mainly in patients diagnosed with schizophrenia who were recruited either from the out-patient clinic or shortly after discharge from in-patient care. Thirdly, some sociodemographic and illness related variables were found to be statistically associated with QOL. There were no published studies in the years prior to the 2003; none were published in the years 2006 , 2008 and 2011 , indicating a scanty research interest in QOL in patients with chronic mental disorders within Nigeria. Our initial search identified an article measuring QOL in Nigerian patients that was published in 2007, but was excluded because it provided no additional relevant information to the study published in 2005 by the same authors.

The WHOQOL-Bref Scale version is a non-disease specific instrument that has been evaluated psychometrically among Nigerian patients with schizophrenia. Ohaeri and colleagues administered the WHOQOL-Bref to 118 patients with schizophrenia who were recently discharged after receiving inpatient care. ${ }^{25}$ They reported that factor analytic study of the instrument indicated that 'overall QOL' should be considered a dependent variable and subjective QOL is an aggregate of different constructs. The WHOQOL-Bref version is the only QOL instrument whose psychometric properties have been explored among Nigerian patients with psychiatric disorders.

Of the 6 studies that were eligible for this review, 4 investigated QOL among patients who were receiving treatment on an out-patient basis ${ }^{26-29}$, while 2 were conducted among patients who were recently discharged from in-patient care. ${ }^{25,30}$ Although, none of the studies we reviewed actually performed a repeat or prospective QOL evaluation, previous studies have shown varied results concerning QOL evaluation in the context of the period that the patients were recruited. Some studies have demonstrated that subjective QOL of patients with psychiatric disorders continue to improve years after been discharged from 
in-patients care. ${ }^{31,32}$ Others have reported that psychiatric disorder patients continue to experience deterioration in QOL after discharge from in-patient facilities. ${ }^{33}$

Two of our studies reported poor correlations between the objective indices and subjective QOL. ${ }^{26,28}$ Studies from developed countries have also shown similar discrepancies between objectively and subjectively assessed QOL in patients with psychiatric disorders. ${ }^{34-36}$ Skantze and colleagues suggested that the reason for this discrepancy was that the same objective event may result in an opposite assessment by the same individual depending on the persons' perspective at the time of the interview. ${ }^{37}$ Another reason suggested was that improvements in objective indices may result in negative subjective responses. ${ }^{38}$

Adewuya and Makanjuola in their study identified the presence of anxiety or depression, unemployment and poor social support as the most important factors in explaining poor subjective QOL. ${ }^{27}$ In another study from a psychiatric facility in North-central Nigeria, Makanjuola and colleagues reported that gender and occupational status were the factors that were statistically associated with subjective QOL in a group of patients receiving treatment for schizophrenia. ${ }^{26}$ Adelufosi and colleagues identified medication nonadherence as the illness-related factor that significantly correlated with lower scores in all the domains of the WHOQOL-Bref. ${ }^{29}$ While, Olusina and Ohaeri in their study published in 2003 reported no statistically significant associations between sociodemographic and illness related factors and QOL. ${ }^{30}$

Studies conducted outside Nigeria have reported varied associations between QOL and different sociodemographic factors in psychiatric patients. In the European Schizophrenia Cohort Study which was a naturalistic investigation of people with schizophrenia living in 3 European countries, correlates of QOL identified include; depression, accommodation status and employment. ${ }^{39}$ Similar QOL correlates have also been identified among Nigerian patients with schizophrenia. ${ }^{26,27}$ Poor social support has been identified as an important determinant of poor subjective QOL among Nigerian patients. ${ }^{27}$ Studies outside Nigeria have reported a similar observation. Lancon and colleagues in a study among patients with schizophrenia in France reported that living with spouses or other family members was found to be significantly associated with better QOL. ${ }^{40}$ Other studies outside Nigeria have also shown that supportive social relationship is positively predictive of higher QOL scores in individuals diagnosed with severe mental illness. ${ }^{41,42}$

The finding by Adelufosi et $\mathrm{al}^{29}$ that medication non adherence was associated with poor subjective QOL has been corroborated by other authors. Lacro and colleagues in a review identified adherence to prescribed medications as an important determinant of QOL in patients with chronic mental illness such as schizophrenia. ${ }^{43}$ Also, it has been suggested by some authors that non adherence to psychotropic medications may indicate the recurrence or exacerbation of symptoms, and the worsening of patients' mental health and consequently their QOL. ${ }^{44}$

\section{Limitations}

This review is limited by the fact that all the studies were crosssectional in nature, thus making it rather difficult to establish the direction of the relationship between QOL and sociodemographic and illness-related factors. Another limitation was that most the studies were conducted in centers located in the South-western region of the country, thus there is the need to be cautious in extending the results to patients with chronic mental disorders in other parts of the country. One other limitation was that our electronic search strategy was confined to only two databases (Pubmed and Medline), other databases such as EMBASE and PsychINFO were not assessed, this could have narrowed the scope of our search thus, resulting into our inability to locate peer-reviewed articles published in journals that were not indexed in either of the databases that we consulted. Most of the eligible studies were conducted among patients with schizophrenia and to a lesser extent, affective disorders. Thus, our use of the terminology "psychiatric disorders" must be interpreted in a restricted sense.

\section{Conclusion}

This review has highlighted a few issues regarding QOL studies in Nigerian patients with psychiatric disorders. The first is that despite the variability observed in these studies, QOL of psychiatric patients is still under researched. Secondly, some of these studies have identified a number of QOL associated sociodemographic and illness-related factors which could be modified to improve a patient's QOL. Further studies are required to evaluate QOL among Nigerian patients suffering from psychiatric disorders other than schizophrenia. Studies are also needed to compare their QOL with those of patients with chronic medical conditions; this will enable the QOL of our patients to be placed in a better perspective. Also, there is need for follow-up QOL studies especially when the initial QOL evaluation indicates an improvement in the immediate period following hospitalization. ${ }^{30}$ Such studies will help identify the factors that may need to be considered in the treatment of our patients that will positively contribute to their QOL. There is also the need to investigate the QOL of caregivers of our patients, since studies conducted in developed countries have shown that the QOL of caregivers is negatively affected due to various physical, emotional and economic factors. ${ }^{45,46}$ This is in addition to the fact, that chronic mental disorders exert a toll on caregivers since the patient's family is primarily responsible for providing support as a result of the shift of burden of care from hospital to families. ${ }^{47} \mathrm{All}$ the reviewed QOL studies in Nigeria have utilized the WHOQOLBref; there is a need for future studies to evaluate the psychometric properties of other generic QOL instruments among Nigerian patients.

\section{References}

1 The WHOQOL Group. The World Health Organization Quality of Life Assessment (WHOQOL): Position Paper From the World Health Organization. Soc Sci Med 1995; 41 (10):1403-1409.

2 Fahey T, Nolan B, Whelan C. Monitoring quality of life in Europe. European Foundation for the Improvement of Living and Working Conditions, office for official publication of the European Communities, 2003.

3 Clark EH. Quality of life: a basis for clinical decision-making in community psychiatric care. J Psychiatr Ment Health Nurs 2004; 11 (6):725-730

4 Bowling A. Measuring health. A review of quality of life measurement scales. 3rd Edition: Open University Press, Berkshire, 2005.

5 Dean H. Multiple instruments for measuring quality of life: Instruments for Clinical Health Care Research. Jones and Barlett Publications Inc, London. 1997: 135-148.

6 Norman RMG, Malla AK, Mclean T, Voruganti LPN, Cortese L, Mcintosh $E$, et al. The relationship of symptoms and level of functioning in 
schizophrenia to general well-being and the Quality of Life Scale. Acta Psychiatr Scand 2000; 102(4):303-309.

7 Orley J, Saxena S, Herman H. Quality of life and mental illness. Reflections from the perspectives of the WHOQOL. Br J Psychiatry 1998;172:291-293.

8 Saxena S, Orley J. Quality of life assessment : The World Health Organization Perspective. Eur Psychiatr 1997;12S3:263s-266s.

9 Sartorius N. Quality of life in Psychiatry. Eur Psychiatr 1996; 11:228-229

10 Angermeyer MC, Holzinger A, Matschinger H, Stengler-Wenzke K. Depression and Quality of Life: Results of a Follow-up Study. Int J Soc Psychiatry 2002;48(3):189-199.

11 Daly EJ, Trivedi MH, Wisniewski SR, Nierenberg AA, Gaynes BN, Warden $D$, et al. Health-related quality of life in depression : A STAR*D report. Ann Clin Psychiatry 2010;22(1): 43-55.

12 Stewart AL, Greenfield S, Hays RD, Wells K, Rogers WH, Berry SD, McGlynn EA, Ware JE. Functional status and well-being of patients with chronic conditions. Results from the Medical Outcomes Study. JAMA 1989;262(7):907-913.

13 Hays RD, Wells KB, Sherbourne CD, Rogers W, Spritzer K. Functioning and well-being outcomes of patients with depression compared with chronic general medical illnesses. Arch Gen Psychiatry 1995;52(1):1 1-19.

14 Sierra P, Livianos L, Rojo L. Quality of life for patients with bipolar disorder ; relationship with clinical and demographic variables. Bipolar Disord 2005;7(2): 159-165.

15 Michalak EE, Yatham LN, Kolesar S, Lam RW. Bipolar disorder and quality of life : a patient-centered perspective. Qual Life Res 2006;15(1): 25-37.

16 Moritz S, Rufer M, Fricke S, Karow A, Morfeld M, Jelinek L, Jacobsen D. Quality of life in obsessive-compulsive disorder before and after treatment. Compr Psychiatry 2005;46(6): 453-459.

17 Mendlowicz MV, Stein MB. Quality of life in individuals with anxiety disorder. Am J Psychiatry 2000;157(5): 669-682.

18 Donovan D. Quality of life as an outcome measure in alcoholism treatment research.J Stud Alcohol 2005;Suppl(15):1 19-139.

19 Rudolf $H$, Watts J. Quality of life in substance abuse and dependency. Int Rev Psychiatr 2002;14(3): 190-197.

20 Ware JE, Sherbourne CD. The MOS 36-item short-from health survey (SF-36).I. Conceptual framework and item selection. Med Care 1992;30(6):473-483.

21 Smith KW, Larson MJ. Quality of life assessments by adult substance abusers receiving publicly funded treatment in Massachusetts. Am J Drug Alcohol Abuse 2003;29(2): 323-335.

22 Akvardar Y, Akdede B, Ozerdem A, Eser E, Topyaka S, Alptekin K. Assessment of quality of life with the WHOQOL-Bref in a group of Turkish psychiatric patients compared with diabetic and healthy subjects. Psychiatry Clini Neurosci 2006;60(6):693-699.

23 Xiang YT, Wang CY, Chiu HF, Zhao JP, Chen Q, Chan SS, Lee EH, Ungvari GS. Sociodemographic and clinical determinants of quality of life in Chinese patients with schizophrenia : a prospective study. Qual Life Res 2010; 19(3):317-322

24 Jascovic-Gasic M, Lackovic M, Dunjic-Kostic B, Pantovic MM, Cvetic T, Damjanovic A, Vukovic O, Cekovic J, Jovanovic AA. Critical review of studies on quality of life in psychiatric patients published in Serbian medical journals from 2000 to 2009. Psychiatr Danub 2010;22(4):488-494.

25 Ohaeri JU, Olusina AK, AlAbassi AH. Factor analytical study of the short version of the World Health Organisation Quality of Life instrument. Psychopathology 2004;37(5): 242-248.

26 Makanjuola AB, Adeponle AB, Obembe AO. Quality of life in patients with schizophrenia in Nigeria. Niger Med Pract 2005;48(2):36-42.

27 Adewrya AO, Makanjuola RO. Subjective quality of life of Nigerian schizophrenia patients : sociodemographic and clinical correlates. Acta Psychiatr Scand 2009; 120(2): 160-164.
28 Adewruya AO, Makanjuola RO. Subjective life satisfaction and objective living conditions of patients with schizophrenia in Nigeria. Psychiatr Serv 2010; 61 (3): 314-316.

29 Adelufosi AO, Adebowale TO, Abayomi O, Mosanya JT. Medication adherence and quality of life among Nigerian outpatients with schizophrenia. Gen Hosp Psychiatry 2012;34(1):72-79.

30 Olusina AK, Ohaeri JU. Subjective quality of life of recently discharged Nigerian psychiatric patients. Soc Psychiatry Psychiatr Epidemiol 2003; 38(12): 707-714.

31 Gerber GJ, Coleman GE, Johnston L, Lafave HG. Quality of life of people with psychiatric disabilities 1 and 3 years after discharge from hospital. Qual life Res 1994;3(6): 379-383.

32 Addington J, Young J, Addington D. Social outcome in early psychosis. Psychol Med 2003; 33(6):1119-1124.

33 Gorna K, Jaracz K, Rybakowski F. Objective and Subjective quality of life in schizophrenic patients after a first hospitalization. Rocz Akad Med Bialymst 2005;50: Suppl 1: 225-227.

34 Barry MM, Crosby C. Quality of life as an evaluative measure in assessing the impact of community care on people with long-term psychiatric disorders. Br J Psychiatry 1996;168(2): 210-216.

35 Warner R. The emics and etics of quality of life assessment. Soc Psychiatry Psychiatr Epidemiol 1999; 34(3): 117 -121.

36 Fitzgerald PB, Williams CL, Cortelling N. et. al. Subject- and observerrated quality of life in schizophrenia. Acta Psychiatr Scand 2001; 103(5): 387-392.

37 Skantze K, Wanke M, Bless H. Subjective assessment and evaluations of change: some lessons from social cognition research. In:Stroebe W,Hewstone M, eds, European Review of Social Psychology.John Wiley \& Sons, New York, 1994: 181-210.

38 Lehman AF. Measures of quality of life among persons with severe and persistent mental disorders. In:Thornicroft G, Tansella M, eds, Mental Health Outcome Measures. Springer, Berlin. 1996:75-92.

39 Mariavaha S, Johnson S, Bebbington P, Angermeyer MC, Brugha T, Azorin JM, et al. Correlates of subjective quality of life in people with schizophrenia : findings from the EuroSC study. J Nerv Ment Dis 2008;196(2): 87-94.

40 Lancon C, Toumi M, Launois R, Anquier P, Llorca PM, Lehman A, et al. Evaluation of the quality of life of schizophrenic patients : validation of the brief version of the Quality of Life Interview. Encephale 2000;26(4):11-16.

41 Lam JA, Rosenheck RA. Correlates of improvement in quality of life among persons who are homeless and have serious mental illness. Psychiatr Serv 2000; 51(1):116-118.

42 Hannson L, Middleboe T, Sorgaar KW, Bengtsson-Tops A, Bjarnason O, Merinder $L$, et al. Living situation, subjective quality of life and social network among individuals with schizophrenia living in community settings. Acta Psychiatri Scand 2002;106(5):343-350.

43 Lacro JP, Dunn LB, Dolder CR, Leckband SG, Jeste DV. Prevalence and risk factors for medication non-adherence in patients with schizophrenia: a comprehensive review of recent literature. J Clin Psychiatry 2002;63(10):892-909

44 Mitchell A, Selmes T. Why don't patients attend their appointments? Maintaining engagement with psychiatric services. Adv Psychiatr Treat 2007;13(6): 423-434.

45 Caqueo-Urizar A, Gutierrez-Maldonado J, Miranda-Castillo C. Quality of life in caregivers of patients with schizophrenia. A literature review. Health Qual Life Outcomes 2009;1 1 (7): 84

46 Fisher M, Kemmier G, Meise U. How Nice that Someone is Interested in me for a Change. Psychatr Prax 2004;31 (2): 60-67.

47 Awad AG, Voruganti LN. The burden of schizophrenia on caregivers: a review. Pharmacoeconomics 2008;26(26): 149-162. 